\title{
Age-related effects on event-related brain potentials in a congruence/incongruence judgment color-word Stroop task
}

\section{Montserrat Zurrón*, Mónica Lindín, Santiago Galdo-Alvarez and Fernando Díaz}

Department of Clinical Psychology and Psychobiology, University of Santiago de Compostela, Santiago de Compostela, Spain

\author{
Edited by: \\ Alex M. Thomson, University College \\ London, UK \\ Reviewed by: \\ Letizia Leocani, Scientific Institute \\ Hospital San Raffaele, Italy \\ Li Xiao Yang, Chongqing Medical \\ University, China \\ *Correspondence: \\ Montserrat Zurrón, Department of \\ Clinical Psychology and \\ Psychobiology, University of Santiago \\ de Compostela, Campus Sur s/n, \\ 15782 Santiago de Compostela, \\ Galicia, Spain \\ e-mail: montserrat.zurron@usc.es
}

We examined the event-related brain potentials elicited by color-word stimuli in a Stroop task in which healthy participants (young and old) had to judge whether the meaning and the color of the stimulus were congruent or incongruent. The Stroop effect occurred in both age groups, with longer reaction times in the older group than in the young group for both types of stimuli, but no difference in the number of errors made by either group. Although the N2 and P3b latencies were longer in the older than in the younger group, there were no differences between groups in the latencies of earlier event-related potential components, and therefore the age-related processing slowing is not generalized. The frontal P150 amplitude was larger, and the parietal P3b amplitude was smaller, in the older than in the younger group. Furthermore, the P3b amplitude was maximal at frontal locations in older participants and at parietal locations in young participants. The age-related increase in perceptual resources and the posterior-to-anterior shift in older adults support adaptive reorganization of the neural networks involved in the processing of this Stroop-type task.

Keywords: aging, Stroop task, event-related potentials

\section{INTRODUCTION}

During normal aging, structural and functional changes are produced in the brain and there is a decline in various cognitive processes, including a decline in performance of executive tasks (Raz, 2005; Reuter-Lorenz and Park, 2010; Fabiani, 2012).

The Stroop task, which is a classical test of executive function, involves presentation of stimuli with two dimensions (word meaning and color) that may conflict (incongruent color-word stimuli, e.g., the word red written in blue) or overlap (congruent colorword stimuli, e.g., the word red written in red). Participants are usually asked to respond to the color of the stimulus and ignore the meaning. Consistently, and regardless of age, the response time is longer for incongruent stimuli than for congruent stimuli (Stroop effect).

The Stroop test is sensitive to the cognitive decline associated with normal aging, as demonstrated by the fact that the behavioral response to congruent and to incongruent stimuli is slower, and the Stroop effect is larger in older people than in young people (see MacLeod, 1991; Van der Elst et al., 2006; Peña-Casanova et al., 2009).

The generalized slowing theory has traditionally been used to explain the behavioral decline observed in the Stroop task in elderly people. This theory is mainly based on reaction times (RTs), which provide a measure of the overall cognitive processing speed. In this theory, it is assumed that the slower information processing in older than in young adults is generalized and gradual from the earliest stages of processing (Salthouse, 1996).

However, studies using the event-related potential (ERP) technique have not supported an age-related general slowing. The ERP technique records changes in the brain electrical activity associated with stimulus processing and with the preparation and execution of motor responses, with a high temporal resolution in the order of milliseconds. This enables examination of the time course of the various stages of stimulus processing.

Falkenstein etal. (2006) found that, in choice RT tasks, the longer RT in elderly than in young adults was exclusively associated with delays in the latency of motor ERP components. Moreover, the N2b and P3b (or P300) components, which are recorded during oddball tasks (in which participants are required to identify an infrequent stimulus that differs from the other, frequent stimulus, in some characteristic) and which are related to stimulus evaluation and categorization processes in working memory, showed delayed latencies in older relative to younger subjects. In contrast, the earlier components associated with the most basic perceptual processes did not show differences between the age groups (Amenedo and Díaz, 1998; for a review, see Friedman, 2012).

Studies that have analyzed the ERP components elicited in response to congruent and incongruent word-color stimuli are scarce and provide inconsistent results. Using a color-word Stroop task, Kray et al. (2005) and Eppinger et al. (2007) found that the $\mathrm{Ni}$ latency was longer in a group of older participants than in a group of young participants $(\mathrm{Ni}$ is a negative wave identified at around 200-600 ms in the incongruent minus congruent difference waveforms); in contrast, West and Alain (2000) found no differences between older and younger adults in the P300 latency.

The congruence/incongruence judgment Stroop task, in which the participants have to decide whether both dimensions of the stimulus (color and meaning of the word) were consistent, has also proved to be sensitive to age effects. In a comparison of a group of middle-aged participants (41-61 years) and a group of young participants (21-39 years), Mager et al. (2007) 
found a longer RT and a larger Strooop effect, as well as longer latencies for the $\mathrm{Ni}$ and N450 ERPs components in the older than in the younger group; however, they did not observe any differences between groups in the latencies of P300 and occipital N1. There were also no differences between groups in the amplitudes of occipital N1; in contrast, the P300 amplitude was smaller in middle-aged than in young participants, and in the former, the amplitude was maximal at $\mathrm{Fz}$, although in the younger participants, the amplitude was maximal at $\mathrm{Pz}$. These data on the P300 amplitude are consistent with observations in older participants in the oddball paradigm (Fabiani and Friedman, 1995; Amenedo and Díaz, 1998; for review, see Friedman, 2012), showing a typical topographic pattern: young-parietal/old-frontal.

In studying the speed of processing in the Stroop test, the advantage of the congruence/incongruence judgment Stoop task is that the participants must focus their attention on both dimensions of the stimulus, which reduces the inhibitory component of the classical task (requiring response to the color and ignoring the meaning of the word), while maintaining the conflict between incongruent color words.

In the present study, we measured RT and number of errors, as well as the latency and amplitude of the ERP components elicited in response to congruent and incongruent color-word stimuli during the execution of a congruence/incongruence judgment Stroop task by young (age range: 19-24 years old) and older participants (age range: 60-79 years old). The aim of the study was to determine whether the age-related slowing in the execution of this type of task is associated with a generalized slowing of stimulus processing or if it only affects certain processes. We also tested whether the amplitude and topography of the P300 followed the pattern (Young-parietal/Old-frontal) previously observed in the oddball paradigm, also observed by Mager et al. (2007) in middle-aged participants during execution of a congruent/incongruent judgment Stroop task.

The working hypotheses were as follows: (1) the RT to the congruent and incongruent color-word stimuli will be longer, and the Stroop effect will be greater in magnitude, in older participants than in young participants, indicating that the processing speed is slower in the older group; (2) there will be no differences between older and younger participants for the latencies of early ERP components; (3) the latencies of late ERP components will be longer in elderly than in young adults, showing that the slowed processing of the color-word stimuli in older people is not generalized and only affects certain processes; and (4) the P300 amplitude will be smaller in older than in younger participants, and the distribution will be parietal in the younger participants and frontal in the older participants.

\section{MATERIALS AND METHODS PARTICIPANTS}

Eleven elderly adults (three female; mean age $=67.6$ years; $\mathrm{SD}=6.4$ ) and eleven young adults (three female; mean age $=20.5$ years; $\mathrm{SD}=1.4$ ), matched in years of education (all university-educated), and with a medium-high socioeconomic status, participated voluntarily in the study. All had normal or corrected to normal vision (but did not use contact lenses).
All were healthy, with no history of neurological or psychiatric disorders or drug abuse, and were not receiving medication at the time of participating in the study (nor had received any in the preceding weeks). The participants were also required to abstain from consuming drugs/alcohol/caffeine and nicotine prior to testing, and none reported fatigue caused by lack of sleep. None of the participants were familiar with the protocols used in the study. All participants were self-reported right-handed.

All participants were recruited from the university population (University of Santiago de Compostela): the young participants were undergraduate students and the older participants were attending courses on scientific and/or artistic subjects aimed at older people and imparted by university lecturers.

The 11 young participants in the study were selected in a semi-random manner (to obtain a sample matched in number of participants, sex, education and socioeconomic status with the older adults group) from an initial sample of 21 participants involved in a previous study (Zurrón et al., 2009).

\section{TASK AND STIMULI}

One hundred and four stimuli were presented to the participants in two blocks (each comprising 52 stimuli), with a rest period of $90 \mathrm{~s}$ between the blocks. The stimuli were the Spanish words "azul” (blue), "verde" (green), "rojo" (red), and "gris" (gray; each word was displayed 26 times), which were printed in one of these four colors on a black background, so that the stimulus features (word color and word meaning) were either congruent (the color and meaning matched) or incongruent (the word and color did not match). Half of the stimuli were congruent and half incongruent. The stimuli were presented in a random order and were displayed for $200 \mathrm{~ms}$, with a $2000 \mathrm{~ms}$ inter-trial interval. The screen was black between the end of one stimulus and the onset of the next.

The color-words were displayed on a flat 19-inch monitor placed one meter from the participant's face. The stimuli were presented in the center of the screen in upper case letters (Helvetica 2 font); each letter was approximately $2 \mathrm{~cm}$ wide and $3.5 \mathrm{~cm}$ high and subtended an angle of $1.15 \times 2.01$ degrees of arc. The participants were asked to press as quickly and accurately as possible, with one hand, a button on a response pad if both dimensions of the stimulus were incongruent, and to press another button, with the other hand, if both dimensions of the stimulus were congruent. Prior to EEG recording, a trial run was carried out with six stimuli to establish whether the participants understood the instructions and responded correctly.

\section{ELECTROENCEPHALOGRAPHY RECORDING}

Prior to the task, each participant was seated in a comfortable chair in an electrically shielded laboratory with attenuated sound and lighting levels. The participants were instructed not to move during the recording session and to look at the center of the screen.

Each participant was fitted with a cap with a nose reference and a frontopolar ground, for recording the EEG activity at 30 electrode sites corresponding to the 10-20 system. Eye movements were recorded simultaneously with additional electrodes placed 
above and below the left eye (VEOG) and at the outer canthus of each eye (HEOG). All impedances were reduced to $5 \mathrm{~K} \Omega$ or less in order to obtain good quality recordings, and care was taken to avoid damaging the participant's scalp.

The EEG signals were passed through a $0.1-30 \mathrm{~Hz}$ band-pass filter before being sampled at $500 \mathrm{~Hz}$; the digitalized signal was then stored. Ocular artifacts were corrected off-line with the algorithm of Semlitsch et al. (1986). Segments of $1600 \mathrm{~ms}$ (200 ms pre-stimulus) were extracted from the EEG, and the pre-stimulus interval was defined as the baseline.

Signals exceeding $\pm 100 \mu \mathrm{V}$ were automatically excluded from the averages, and only the epochs corresponding to the stimuli with correct responses were taken into account. Between 45 and 50 epochs were included in the ERP averages for each type of stimulus (congruent and incongruent), and there were no differences between the numbers of epochs for either type of stimulus or age group.

\section{DATA ANALYSIS}

After visual inspection of the grand averages, we identified the frontal P150-occipital N170 complex in the 120-180 ms post-stimulus time interval (see Joyce and Rossion, 2005, for a demonstration that both waves comprise a single component). The P150 peak latency and amplitude were measured at Fz, whereas N170 parameters were measured at $\mathrm{Oz}$ (see Figure 1).

N2 showed a wider scalp distribution in older than in young participants (see Figure 2). The N2 peak amplitude was measured at $\mathrm{Fz}$ and $\mathrm{Cz}$ locations, as this wave was better defined in both age groups at these electrode sites, and the N2 peak latency was measured at $\mathrm{Cz}$ electrode site. At $\mathrm{Pz}$ and $\mathrm{Oz}$ electrodes sites, the $\mathrm{N} 2$ component was only identified in the older participants (see Figure 1). The N2 component was always identified as a negative voltage wave, which occurred prior to the $\mathrm{P} 3 \mathrm{~b}$ component, in the 200-350 ms post-stimulus interval. Once it was confirmed that P3b was reliably identified at all the midline electrode sites in the 360-600 ms post-stimulus interval, the P3b peak amplitude was measured at $\mathrm{Fz}, \mathrm{Cz}$ and $\mathrm{Pz}$, whereas peak latency was only measured at $\mathrm{Cz}$ electrode site.

In the ERP waveforms of the young participants (see Figure 1), we observed three positive components (between 300 and $800 \mathrm{~ms}$ ) that had been identified in a previous study (Zurrón et al., 2009): first P3, P3b, and PSW. Of these, only the P3b component was identified at $\mathrm{Fz}, \mathrm{Cz}$, and $\mathrm{Pz}$ electrode sites. The first $\mathrm{P} 3$ component was recorded at $\mathrm{Pz}$ and $\mathrm{Oz}$, at between 290 and $330 \mathrm{~ms}$; the PSW was centroparietal with maximal peak amplitude between 540 and $600 \mathrm{~ms}$. In contrast, in the older participants we only observed a positive component at the three midline electrodes, between 300 and $800 \mathrm{~ms}$, (P3b component). Therefore, in the present study, we only evaluated the parameters of the P3b component in the latency range between 300 and $800 \mathrm{~ms}$, as this was the only component identified in both young and older participants.

\section{STATISTICAL ANALYSES}

The RTs, the number of errors, the peak latencies of P150, N170, $\mathrm{N} 2$ and P3b, and the amplitude of P150 and N170 were examined by mixed analysis of variances (ANOVAs), with Group as the between-subject factor (two levels: young and old groups), and Congruence as the within-subject factor (two levels: congruent and incongruent).

As $\mathrm{N} 2$ and $\mathrm{P} 3 \mathrm{~b}$ components presented a wider scalp distribution than P150 y N170, N2, and P3b was measured in more than one electrode site, and therefore the statistical analyses included the within-subject factor Electrode. Thus, the amplitudes of N2 and P3b components were analyzed by mixed ANOVAs, with Group as the between-subject factor (two levels: young and old groups) and Congruence (two levels: congruent and incongruent) and Electrode (two levels for $\mathrm{N} 2: \mathrm{Fz}$ and $\mathrm{Cz}$, and three levels for $\mathrm{P} 3 \mathrm{~b}: \mathrm{Fz}$, $\mathrm{Cz}$, and $\mathrm{Pz}$ ) as within-subject factors.

Whenever the ANOVAs revealed significant results, pairwise comparison of means (adjusted to Bonferroni correction) was carried out to identify the source of the differences. GreenhouseGeisser corrections were applied to the degrees of freedom in all cases in which the condition of sphericity was not met. In these cases, the original degrees of freedom were presented together with the corrected $\mathrm{p}$ and $\epsilon$ values. Differences were considered significant at $p \leq 0.05$. All statistical analyses were carried out with SPSS (version 19.0).

The RT data and the number of errors committed by two older participants were not stored correctly in the recording session and the data were lost. Some ERP latency and amplitude values were also lost as it was not possible to identify all components in the 22 participants. However, all analyses included data from at least eight participants per group.

\section{RESULTS \\ PERFORMANCE (SEE TABLE 1)}

The mean values and standard deviations (SDs) of the RT and the number of errors made by participants in both groups are shown in Table 1. It can be noticed that the older group showed longer RTs than the young group, and also longer RTs for incongruent than for congruent stimuli (Stroop effect). Notably, SD was larger for elderly than for young participants in RT, an index of the greater variability of response in the first group.

\section{Reaction time}

The mixed ANOVA (Group $\times$ Congruence) revealed that the Group factor $[F(1,18)=28.5, p<0.001]$, the Congruence factor $[F(1,18)=56.5, p<0.001]$, and the Group $\times$ Congruence interaction $[F(1,18)=6.67, p \leq 0.019]$ had significant effects on RT. The RTs were significantly longer in the elderly group than in the young group, and they were also significantly longer for incongruent stimuli than for congruent stimuli. As the Group $\times$ Congruence interaction was significant, we investigated whether the magnitude of the Stroop effect was greater in the older participants than in the young participants. For this purpose, we subtracted the RT to the congruent stimuli from the RT to the incongruent stimuli (mean for older participants $=123.7 \mathrm{~ms}$, mean for young participants $=60.4 \mathrm{~ms}$ ), and we analyzed the differences between groups with a $t$-test for independent samples $[t(18)=-2.4, p \leq 0.034]$ : the values of this variable were significantly larger for the older group than for the younger group. Therefore, the magnitude of 


\section{YOUNG GROUP}
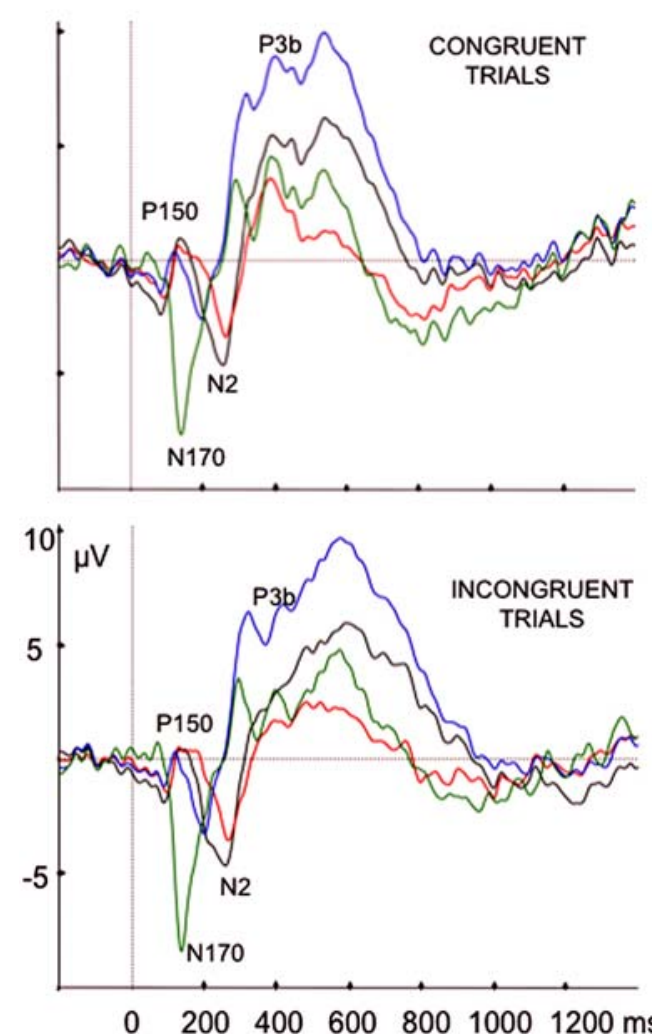

OLD GROUP
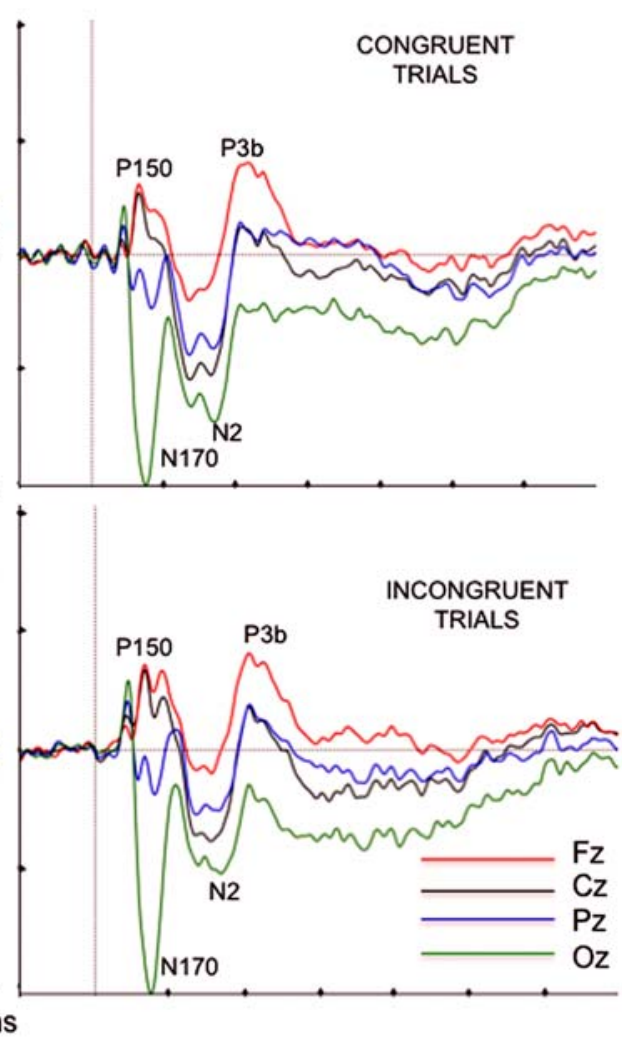

FIGURE 1 | Grand average ERP waveforms, at Fz, Cz, Pz, and Oz electrode sites, elicited by congruent color words and incongruent color words in the young and old participants.

the Stroop effect was significantly greater in the older participants than in the young participants.

\section{Number of errors}

No significant effects of the factors or of their interactions were found for the number of errors.

\section{EVENT-RELATED POTENTIALS (SEE TABLES 2 AND 3, AND FIGURES 1 AND 2)}

The mean values (and the SD) of the latencies and amplitudes of the ERP components are shown in Tables 2 and 3. The ERP waveforms (Figure 1) and the maps of voltages and current densities (at the peak latency of each component; Figure 2) are shown for each group and type of stimulus.

\section{Latencies}

The mixed ANOVAs (Group $\times$ Congruence) did not show any significant effect of the factors or their interaction on P150 and N170 latencies.

The mixed ANOVAs revealed that the Group factor had a significant effect on $\mathrm{N} 2$ latency $[F(1,20)=25.6, p<0.001]$ and $\mathrm{P} 3$ latency $[F(1,20)=5.12, p<0.035]$, which was significantly longer in older adults than in young adults.

\section{Amplitudes}

The mixed ANOVA (Group $\times$ Congruence) revealed that the Group factor $[F(1,16)=15.1, p \leq 0.001]$ had a significant effect on the P150 amplitude, which was significantly larger in older adults than in young adults.

The mixed ANOVA did not show any significant effect of the factors or of their interaction on N170 amplitude.

In relation to $\mathrm{N} 2$ amplitude, the ANOVA (Group $\times$ Congruence $\times$ Electrode) revealed that Electrode factor $[F(1,19)=10.46$, $p \leq 0.004]$, and the Group $\times$ Congruence interaction $[F(1,19)=4.77, p \leq 0.042]$ were significant. The $\mathrm{N} 2$ amplitude was significantly larger at the $\mathrm{Cz}$ than at the $\mathrm{Fz}$ electrode site, and only in the elderly adults it was significantly smaller to incongruent than to congruent stimuli $(p \leq 0.019)$.

For the P3b amplitude, the ANOVA (Group $\times$ Congruence $\times$ Electrode) revealed significant effects of the factor Electrode $[F(2,40)=4.76, \epsilon=0.7, p \leq 0.025]$, and the Group $\times$ Electrode $[F(2,40)=17.49, p<0.001]$ and Group $\times$ Congruence $[F(1,20)=4.44, p \leq 0.048]$ interactions. The mean pairwise comparisons showed that the amplitudes were significantly smaller in response to incongruent than to congruent stimuli only in the young adults $(p \leq 0.05)$; at $\mathrm{Pz}$, the amplitudes were significantly smaller in the older group than 


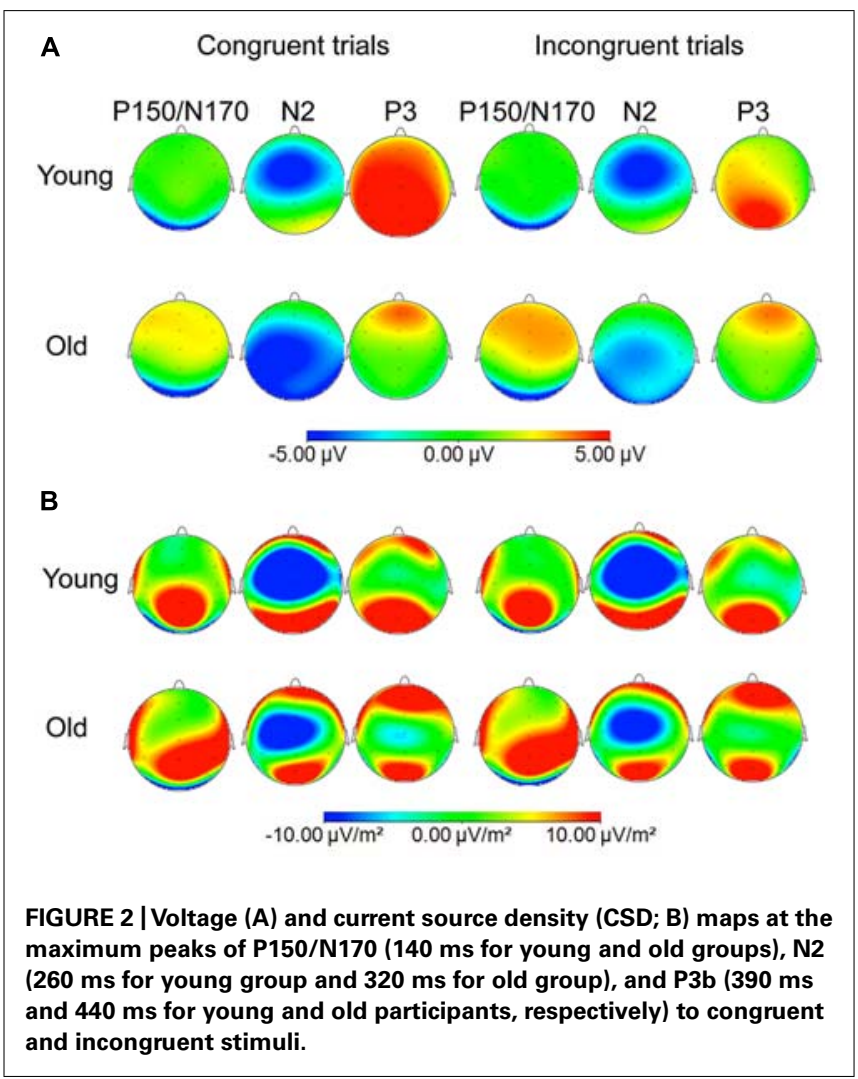

in the young group ( $p \leq 0.001$ ); and in the young adults the amplitude at $\mathrm{Pz}$ was significantly larger than at $\mathrm{Fz}(p \leq 0.001)$ and $\mathrm{Cz}(p \leq 0.001)$, whereas in older adults the amplitude was significantly larger at $\mathrm{Fz}$ than at $\mathrm{Cz}(p \leq 0.031)$ and at $\mathrm{Pz}$ $(p \leq 0.05)$.

\section{DISCUSSION}

\section{PERFORMANCE}

In the Stroop congruence/incongruence judgment task, the RTs to both types of stimuli (congruent and incongruent) were longer, and the magnitude of the Stroop effect was greater in the older than in the younger participants. This is consistent with the findings reported by Mager et al. (2007) for a comparison between young and middle-aged participants, and with the differences between young and elderly adults observed in the classic versions of the Stroop task (see MacLeod, 1991; Van der Elst et al., 2006; PeñaCasanova et al., 2009). The results also support our first working hypothesis (see Introduction).

Hasher and Zacks (1988) reported that a reduced ability to inhibit irrelevant information in older adults explained the poorer performance of the Stroop task by older than by young participants. However, our results do not support this explanation, for the following reasons. First, our congruence/incongruence judgment task removes the inhibitory component for the meaning of the word; consequently, the delayed behavioral response in elderly people relative to young people, in the Stroop-type task, may be due to an age-related decrease in processing speed (Verhaeghen and De Meersman, 1998). Second, there were no differences between the two age groups in the number of errors, which is consistent with data suggesting that the effect of aging is more closely related to the speed of response than to accuracy measures (Van der Elst et al., 2006), perhaps because accuracy prevails over speed in older people.

\section{ERP LATENCIES}

We did not find any differences between older and young participants in the latencies of the early components P150 and N170. However, the latencies of the late components N2 and P3b were longer in the older than in the young participants. These results therefore confirm that the slowed information processing in the Stroop task is not generalized in older people.

The frontal P150-occipital N170 complex has been associated with processing of complex visual stimuli such as words and faces (Schendan et al., 1998; Bentin etal., 1999; Rossion et al., 2003; Joyce and Rossion, 2005; Dien, 2009). Of the two components that form the complex, N170 is the most commonly studied. Thus, N170 in response to words is considered specifically related to sublexical perceptual processes (Dien, 2009). As no differences were observed between groups in the P150-N170 complex latencies, the neural processing of word-color stimuli may not be slower in older than in young people, at least until this stage of perceptual processing.

$\mathrm{N} 2$ and P3b components are observed in all tasks in which attention must be focused in order to make a decision (Ritter et al., 1979; Luck and Kappenman, 2012), and they have been associated with evaluation and categorization of the stimuli in

Table 1 | Mean values and standard deviations (in brackets) for RT (in ms) and number of errors, in response to congruent (C) and incongruent (IC) stimuli, in old and young participants.

\begin{tabular}{|c|c|c|c|c|c|}
\hline Old & 827 (134) & 951 (170) & $* * * 124$ & $2.9(2)$ & $1.7(2)$ \\
\hline Old vs. Young & **240 & ***304 & ${ }^{*} 64$ & - & - \\
\hline
\end{tabular}

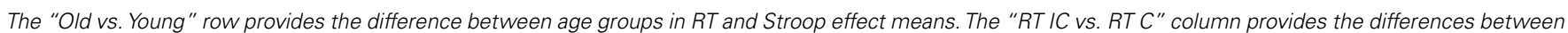

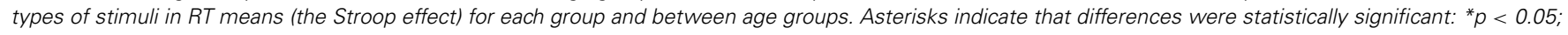
${ }^{*} p<0.01 ; *{ }^{*} p<0.001$. 
working memory (Kutas et al., 1977; Hillyard and Kutas, 1983; Folstein and van Petten, 2008).

In the present study, in line with our hypotheses and with the results obtained for some studies using the oddball paradigm (for reviews, see Polich, 1996; Friedman, 2012), the N2 and P3b latencies were longer in older than in young participants. This appears to support the idea that the neural networks underlying cognitive processes of evaluation and categorization of color-word stimuli act more slowly in older than in young participants.

The age-related delays in N2 and P3b latencies (around $60 \mathrm{~ms}$ for both components and stimulus conditions) account for only a part of the RT delay in the older group relative to the young group, as the average difference was 264 and $328 \mathrm{~ms}$ for congruent and incongruent stimuli, respectively. Consequently, most of the delay in RT might be attributed to the response preparation and execution stages, which is consistent with previous results (Falkenstein et al., 2006).

Future studies should focus on the delay in the RT associated with response processes, by obtaining movement-related potentials, especially considering that the variability in RT is of greater magnitude in older than in young participants. For example, it would be interesting to contrast the effect of motor preparation comparing silent responses tasks (see Amato et al., 2013) with overt responses tasks. In addition, the study of motor ERP components would probably shed light on the causes of the increased magnitude of the Stroop effect obtained in older with respect to young participants.

\section{ERP AMPLITUDES}

With respect to the amplitudes, we observed important differences between young and older participants. The frontal P150 amplitude was larger in the older participants than in the young participants.

Table 2 | Mean values and standard deviations (in brackets) for P150, $\mathrm{N} 170, \mathrm{~N} 2$, and $\mathrm{P} 3 \mathrm{~b}$ latencies (in ms), to congruent and incongruent stimuli, in old and young participants.

\begin{tabular}{llllll}
\hline & & $\mathbf{P 1 5 0}(\mathbf{F z})$ & $\mathbf{N 1 7 0}(\mathbf{O z})$ & $\mathbf{N 2}(\mathbf{C z})$ & $\mathbf{P 3 b}(\mathbf{C z})$ \\
\hline Young & Congruent & $148(14)$ & $145(26)$ & $262(32)$ & $391(19)$ \\
& Incongruent & $141(15)$ & $145(25)$ & $258(28)$ & $412(52)$ \\
\multirow{2}{*}{ Old } & Congruent & $140(16)$ & $152(17)$ & $322(31)$ & $440(44)$ \\
& Incongruent & $143(21)$ & $151(14)$ & $325(31)$ & $427(37)$
\end{tabular}

This may indicate that the older participants dedicated more neural resources to sub-lexical perception of the color-words than the young participants.

The $\mathrm{P} 3 \mathrm{~b}$ amplitude at $\mathrm{Pz}$ was larger in the younger group than in the older group, this result is consistent with previous findings and with our hypothesis. Walhovd et al. (2008) showed that the reduction in $\mathrm{P} 3 \mathrm{~b}$ amplitude in elderly relative to young participants in oddball tasks was not caused by a latency-jitter effect but that it was a genuine phenomenon of the aging process. These authors attributed the result to a reduction in the neural resources allocated to the process of categorization of the target stimuli with age. In the context of the Stroop task, the P3b amplitude is sensitive to categorization of color words as congruent or incongruent (Zurrón et al., 2009). Thus, smaller P3b amplitudes in response to both types of color-word stimuli in older than in younger participants may indicate that the older participants had fewer resources available to dedicate to the categorization process.

We also observed differences between the two groups of participants with respect to the ERP amplitude in response to congruent and incongruent stimuli. In older participants, the N2 amplitude was smaller to incongruent stimuli than to congruent stimuli. In young participants, the amplitude of P3b was smaller to incongruent stimuli than to congruent stimuli, in accordance with previous findings (see Zurrón et al., 2009). Unlike the young participants, older participants did not show any differences in P3b amplitude between incongruent and congruent stimuli, perhaps because of a possible ceiling effect, given the small magnitude of P3b in older participants. The smaller amplitudes to incongruent than to congruent stimuli may be interpreted in terms of greater difficulty in evaluating and classifying the incongruent stimuli, as the amplitude of P3b decreases with the difficulty of the task (Donchin, 1981; Johnson, 1986; Donchin and Coles, 1988; Verleger, 1988).

Moreover, the topographical distribution of $\mathrm{P} 3 \mathrm{~b}$ was different in the two groups, thus confirming our hypothesis: in the older participants, the $\mathrm{P} 3 \mathrm{~b}$ amplitude was maximal at frontal locations, whereas in young participants it was maximal at parietal locations. These differences between groups can be seen in the ERP waveforms, as well as in the voltage and current density maps.

The more frontal topographical distribution of the P3b with age, the reduced $\mathrm{P} 3 \mathrm{~b}$ amplitude in older than in young adults in parietal but not in frontal electrode sites, and the larger amplitude of $\mathrm{P} 150$ at $\mathrm{Fz}$ in the older than in the young participants may reflect overactivation of frontal areas, which is consistent with

Table 3 | Mean values and standard deviations (in brackets) for P150, N170, N2, and P3b amplitudes (in $\mu \mathrm{V}$ ), to congruent and incongruent stimuli, in old and young participants.

\begin{tabular}{lllllllll}
\hline & & $\mathbf{P 1 5 0}(\mathbf{F z})$ & $\mathbf{N 1 7 0}(\mathbf{O z})$ & $\mathbf{N 2}(\mathbf{F z})$ & $\mathbf{N 2}(\mathbf{C z})$ & $\mathbf{P 3 b}(\mathbf{F z})$ & $\mathbf{P 3 b}(\mathbf{C z})$ & $\mathbf{P 3 b}(\mathbf{P z})$ \\
\hline \multirow{2}{*}{ Young } & Congruent & $2.1(1.6)$ & $-10.9(5.7)$ & $-4(3.2)$ & $-6.2(4.5)$ & $4.3(2.9)$ & $5.9(3.7)$ & $9.8(4.6)$ \\
& Incongruent & $1.9(1.3)$ & $-11.1(6.9)$ & $-4.4(2.9)$ & $-6.4(4.7)$ & $3.2(2.9)$ & $4.3(3.7)$ & $8.5(4.4)$ \\
\multirow{2}{*}{ Old } & Congruent & $4.3(1.7)$ & $-11.6(7.5)$ & $-2.4(4.2)$ & $-6.9(5)$ & $5.3(3.3)$ & $3.1(3.4)$ & $2.8(3.1)$ \\
& Incongruent & $4.6(1.3)$ & $-11.5(7.9)$ & $-1.2(3)$ & $-4.6(4.1)$ & $5.8(2.9)$ & $3.7(3.1)$ & $3.5(2.7)$
\end{tabular}


the posterior-anterior shift in aging (PASA) hypothesis (Grady et al., 1994; Davis et al., 2008). The PASA hypothesis is included within the scaffolding theory of aging and cognition (STAC; see Park and Reuter-Lorenz, 2009), which suggests that the neural networks that sustain cognitive processes undergo modifications to adapt to the changes produced in the brains of older participants and to maintain functions as well as possible, although the new scaffolded networks may be less efficient than the original ones.

In summary, the RT data indicate that older participants processed information more slowly than younger participants in a Stroop congruence/incongruence judgment task. Psychophysiological data obtained with the ERP technique indicate that the age-related slowing is not generalized, since it does not affect the neural networks underlying perceptual processes, but that it does affect the neural networks underlying evaluation and categorization cognitive processes. Moreover, the ERP data confirm changes in the neural functioning of the older participants during the processing of a congruence/incongruence judgment color-word Stroop task. As the number of errors was similar in both age groups, such neurofunctional changes might be explained by a compensatory reorganization of brain neural networks with aging, consistent with the neural scaffolding hypothesis.

\section{ACKNOWLEDGMENTS}

This study was financially supported by funds from the Spanish Government: Ministerio de Economía y Competitividad (PSI2010-22224-C03-03); and by the Galician Government: Consellería de Economía e Industria (10 PXIB 211070 PR), and Consellería de Cultura, Educación e Ordenación Universitaria (Axudas para a Consolidación e Estruturación de unidades de investigación competitivas do sistema universitario de Galicia. Ref: CN 2012/033; with FEDER funds).

\section{REFERENCES}

Amato, N., Riva, N., Cursi, M., Martins-Silva, A., Martinelli, V., Comola, M., et al. (2013). Different frontal involvement in ALS and PLS revealed by Stroop event-related potentials and reaction times. Front. Aging Neurosci. 5:82. doi: $10.3389 /$ fnagi.2013.00082

Amenedo, E., and Díaz, F. (1998). Aging-related changes in processing of non-target and target stimuli during an auditory oddball task. Biol. Psychol. 48, 235-267. doi: 10.1016/S0301-0511(98)00040-4

Bentin, S., Mouchetant-Rostaing, Y., Giard, M. H., Echallier, J. F., and Pernier, J. (1999). ERP manifestation of processing printed words at different psycholinguistic levels: time course and scalp distribution. J. Cogn. Neurosci. 11, 235-260. doi: 10.1162/089892999563373

Davis, S. W., Dennis, N. A., Daselaar, S. M., Fleck, M. S., and Cabeza, R. (2008). Qué PASA? The posterior-anterior shift in aging. Cereb. Cortex 18, 1201-1209. doi: 10.1093/cercor/bhm 155

Dien, J. (2009). The neurocognitive basis of reading single words as seen through early latency ERPs: a model of converging pathways. Biol. Psychol. 80, 10-22. doi: 10.1016/j.biopsycho.2008.04.013

Donchin, E. (1981). Surprise!...Surprise? Psychopysiology 18, 493-513. doi: 10.1111/j.1469-8986.1981.tb01815.x

Donchin, E., and Coles, M. G. H. (1988). Is the P300 component a manifestation of context updating? Behav. Brain Sci. 11, 355-372. doi: 10.1017/S0140525X00058027

Eppinger, B., Kray, J., Mecklinger, A., and John, O. (2007). Age differences in task switching and response monitoring: evidence from ERPs. Biol. Psychol. 75, 52-67. doi: 10.1016/j.biopsycho.2006.12.001
Fabiani, M. (2012). It was the best of times, it was the worst of times: a psychophysiologist's view of cognitive aging. Psychophysiology 49, 283-304. doi: 10.1111/j.1469-8986.2011.01331.x

Fabiani, M., and Friedman, D. (1995). Changes in brain activity patterns in aging: the novelty oddball. Psychophysiology 32, 579-594. doi: 10.1111/j.14698986.1995.tb01234.x

Falkenstein, M., Yordanova, J., and Kolev, V. (2006). Effects of aging on slowing of motor-response generation. Int. J. Psychophysiol. 59, 22-29. doi: 10.1016/j.ijpsycho.2005.08.004

Folstein, J. R., and van Petten, C. (2008). Influence of cognitive control and mismatch on the N2 component of the ERP: a review. Psychophysiology 45, 152-170. doi: 10.1111/j.1469-8986.2007.00602.x

Friedman, D. (2012). "The components of aging," in Oxford Handbook of EventRelated Potential Component, eds S. J. Luck and E. S. Kappenman (New York: Oxford University Press), 513-536.

Grady, C. L., Maisog, J. M., Horwitz, B., Ungerleider, L. G., Mentis, M. J., Salerno, J. A., et al. (1994). Age-related changes in cortical blood flow activation during visual processing of faces and location. J. Neurosci. 14, 1450-1462.

Hasher, L., and Zacks, R. (1988). "Working memory, comprehension, and aging: a review and a new view," in The Psychology of Learning and Motivation: Advances in Research and Theory, ed. G. Bower (San Diego, CA: Academic Press), 193-225.

Hillyard, S. A., and Kutas, M. (1983). Electrophysiology of cognitive processing. Annu. Rev. Psychol. 34, 33-61. doi: 10.1146/annurev.ps.34.020183.000341

Johnson, R. Jr. (1986). A triarchic model of P300 amplitude. Psychopgysiology 23, 367-384.

Joyce, C., and Rossion, B. (2005). The face-sensitive N170 and VPP components manifest the same brain processes: the effect of reference electrode. Clin. Neurophysiol. 116, 2613-2631. doi: 10.1016/j.clinph.2005.07.005

Kray, J., Eppinger, B., and Mecklinger, A. (2005). Age differences in attentional control: an event-related potential approach. Psychophysiology 42, 407-416. doi: 10.1111/j.1469-8986.2005.00298.x

Kutas, M., McCarthy, G., and Donchin, E. (1977). Augmenting mental chronometry: the P300 as a measure of stimulus evaluation time. Science 197, 792-795. doi: $10.1126 /$ science. 887923

Luck, S. J., and Kappenman, E. S. (2012). "ERP components and selective attention," in Oxford Handbook of Event-Related Potential Components, eds S. J. Luck and E. S. Kappenman (New York: Oxford University Press), 295-329.

MacLeod, C. M. (1991). Half a century of research on the Stroop effect: an integrative review. Psychol. Bull. 109, 163-203. doi: 10.1037/0033-2909.109.2.163

Mager, R., Bullinger, A. H., Brand, S., Schmidlin, M., Schärli, H., MüllerSpahn, F., etal. (2007). Age-related changes in cognitive conflict processing: an event-related potential study. Neurobiol. Aging 28, 1925-1935. doi: 10.1016/j.neurobiolaging.2006.08.001

Park, D. C., and Reuter-Lorenz, P. (2009). The adaptive brain: aging and neurocognitive scaffolding. Annu. Rev. Psychol. 60, 173-196. doi: 10.1146/annurev.psych.59.103006.093656

Peña-Casanova, J., Quiñones-Úbeda, S., Gramunt-Fombuena, N., Quintana, M., Aguilar, M., Molinuevo, J. L., et al. (2009). Spanish Multicenter Normative Studies (NEURONORMA Project): norms for the Stroop color-word interference test and the Tower of London-Drexel. Arch. Clin. Neuropsychol. 24, 413-429. doi: 10.1093/arclin/acp043

Polich, J. (1996). Meta-analysis of P300 normative aging studies. Psychophysiology 33, 334-353. doi: 10.1111/j.1469-8986.1996.tb01058.x

Raz, N. (2005). "The aging brain observed in vivo: differential changes and their modifiers," in Cognitive Neuroscience of Aging, eds R. Cabeza, L. Nyberg, and D. Park (New York: Oxford University Press), 19-569.

Reuter-Lorenz, P., and Park, D. C. (2010). Human neuroscience and the aging mind: a new look at old problems. J. Gerontol. Psychol. Sci. 65, 405-415. doi: 10.1093/geronb/gbq035

Ritter, W., Simson, R., Vaughan, G. H., and Friedman, D. (1979). A brain event related to the making of a sensory discrimination. Science 203, 1358-1361. doi: $10.1126 /$ science. 424760

Rossion, B., Joyce, C. A., Cottrell, G. W., and Tarr, M. J. (2003). Early lateralization and orientation tuning for face, word, and object processing in the visual cortex. Neuroimage 20, 1609-1624. doi: 10.1016/j.neuroimage.2003. 07.010 
Salthouse, T. A. (1996). The processing-speed theory of adult age differences in cognition. Psychol. Rev. 103, 403-428. doi: 10.1037/0033-295X.103. 3.403

Schendan, H. E., Ganis, G., and Kutas, M. (1998). Neuropsychological evidence for visual perceptual categorization of words and faces within $150 \mathrm{~ms}$ Psychophysiology 35, 340-351. doi: 10.1111/1469-8986.3530240

Semlitsch, H. V., Anderer, P., Schuster, P., and Presslich, O. (1986). A solution for reliable and valid reduction of ocular artefacts applied to the P300 ERP. Psychophysiology 23, 695-703. doi: 10.1111/j.1469-8986.1986. tb00696.x

Van der Elst, W., Van-Boxtel, M. P. J., Van-Breukelen, G. J. P., and Jolles, J. (2006). The Stroop color-word test: influence of age, sex, and education; and normative data for a large sample across the adult age range. Assessment 13, 62-79. doi: $10.1177 / 1073191105283427$

Verhaeghen, P., and De Meersman, L. (1998). Aging and the Stroop effect: a metaanalysis. Psychol. Aging 13, 120-126. doi: 10.1037/0882-7974.13.1.120

Verleger, R. (1988). Event-related potentials and memory: a critique of the context updating hypothesis and an alternative interpretation of P3. Behav. Brain Sci. 11, 341-354. doi: 10.1017/S0140525X00058015

Walhovd, K. B., Rosquist, H., and Fjell, A. M. (2008). P300 amplitude age reductions are not caused by latency jitter. Psychophysiology 45, 545-553. doi: 10.1111/j.14698986.2008.00661.x
West, R., and Alain, C. (2000). Age-related decline in inhibitory control contributes to the increased Stroop effect observed in older adults. Psychophysiology 37, 179189. doi: 10.1111/1469-8986.3720179

Zurrón, M., Pouso, M., Lindín, M., Galdo, S., and Díaz, F. (2009). Event-related potentials with the Stroop colour-word task: timing of semantic conflict. Int. J. Psychophysiol. 72, 246-252. doi: 10.1016/j.ijpsycho.2009.01.002

Conflict of Interest Statement: The authors declare that the research was conducted in the absence of any commercial or financial relationships that could be construed as a potential conflict of interest.

Received: 23 January 2014; accepted: 30 May 2014; published online: 17 June 2014. Citation: Zurrón M, Lindín M, Galdo-Alvarez S and Díaz F (2014) Age-related effects on event-related brain potentials in a congruence/incongruence judgment color-word Stroop task. Front. Aging Neurosci. 6:128. doi: 10.3389/fnagi.2014.00128 This article was submitted to the journal Frontiers in Aging Neuroscience.

Copyright (0) 2014 Zurrón, Lindín, Galdo-Alvarez and Díaz. This is an open-access article distributed under the terms of the Creative Commons Attribution License (CC BY). The use, distribution or reproduction in other forums is permitted, provided the original author(s) or licensor are credited and that the original publication in this journal is cited, in accordance with accepted academic practice. No use, distribution or reproduction is permitted which does not comply with these terms. 